\title{
foF2 Seasonal Asymmetry Diurnal Variation Study during Very Quiet Geomagnetic Activity at Dakar Station
}

\author{
Sibri Alphonse Sandwidi, Doua Allain Gnabahou (iD, and Frédéric Ouattara \\ Laboratoire de Recherche en Energétique et Météorologie de l'Espace (LAREME) de l'Université Norbert ZONGO, \\ BP 376 Koudougou, Burkina Faso \\ Correspondence should be addressed to Doua Allain Gnabahou; gnabahou@yahoo.fr
}

Received 22 July 2020; Revised 9 October 2020; Accepted 14 October 2020; Published 28 October 2020

Academic Editor: Angelo De Santis

Copyright (C) 2020 Sibri Alphonse Sandwidi et al. This is an open access article distributed under the Creative Commons Attribution License, which permits unrestricted use, distribution, and reproduction in any medium, provided the original work is properly cited.

\begin{abstract}
This paper aims to study the foF2 seasonal asymmetry diurnal variation at Dakar station from 1976 to 1995 . We show that equinoctial asymmetry is less pronounced and somewhere is absent throughout 21 and 22 solar cycles. The absence of equinoctial asymmetry may be due to Russell-McPherron mechanism and the vertical drift $E \times B$. The solstice anomaly or annual anomaly is always observed throughout both 21 and 22 solar cycles as measured at Dakar ionosonde. The maximum negative value of $\sigma \mathrm{foF} 2$, fairly equal to $-65 \%$, is observed during the decreasing phase at solstice time; this value appeared usually at $0200 \mathrm{LT}$ except during the maximum phase during which it is observed at $2300 \mathrm{LT}$. The maximum positive value, fairly equal to $+94 \%$, is observed at 0600 LT during solar minimum at solstice time. This annual asymmetry may be due to neutral composition asymmetric variation and solar radiation annual asymmetry with the solstice time. The semiannual asymmetry is also observed during all solar cycle phases. The maximum positive value $(+73 \%)$ is observed at $2300 \mathrm{LT}$ during solar maximum, and its maximum negative $(-12 \%)$ is observed during the increasing phase. We established, as the case of annual asymmetry, that this asymmetry could not be explained by the asymmetry in vertical velocity $E \times B$ phenomenon but by the axial mechanism, the "thermospheric spoon" mechanism, and the seasonally varying eddy mixing phenomenon.
\end{abstract}

\section{Introduction}

Ionosphere's F2 layer performs an important function concerning high frequency (HF) radiocommunication. Since the success of transatlantic radio transmission of Marconi in 1901, several studies on ionosphere parameter variation have been undertaken. Many of them focused on seasonal asymmetry observed in F2 layer parameters such as the peak electron density $(\mathrm{NmF} 2)$, the total electron content (TEC), or the critical F2 layer frequency (foF2) [1-17]. The present paper is aimed at investigating the asymmetry observed during equinoctial and solstice time at Dakar station (Lat: $14.8^{\circ} \mathrm{N}$; Long: $342.6^{\circ} \mathrm{E}$ ), an African Equatorial Ionization Anomaly (EIA) region station, by using foF2 values computed in this ionosonde station. The period of investigation covers solar cycles 21 (SC 21) and 22 (SC 22), from 1976 to 1995, and concerns the four solar phases (minimum, increasing, maximum, and decreasing phases). This investigation concerns very quiet geomagnetic activity (VQA). Equinoctial asymmetry is explained by three mechanisms: (1) axial mechanism [18, 19], (2) equinoctial mechanism [2, 18-21], and (3) Russell-McPherron mechanism [15]. This study's goal is to point out among those mechanisms, which can be used in the case of Dakar ionosonde station. Solstice asymmetry called by [22] annual asymmetry or nonseasonal asymmetry is generally explained by the variation of Sun-Earth distance. This variation can be due to (1) the variation of $\mathrm{O} / \mathrm{O}_{2}$ ratio that modulates the electron loss coefficient in the F2 layer [23] which is called "Buonsanto's hypothesis" [22], (2) the 7\% variation in the flux of ionization, and (3) interplanetary corpuscular radiation [24]. We will see which process can be invoked for this type of asymmetry.

The paper outline is as follows: the second section concerns data and methods of analysis, the third section treats our results and discussions, and a conclusion ends it. 


\section{Data and Methods}

2.1. Data. For this paper, the data involved are (1) foF2 values carried out at Dakar station for ionosphere time variation. This station is operated from 1950 to December 1996. The involved data interval for our study is 1976-1995 and concerned SC 21 and SC 22; (2) Zurich sunspot number (Rz) for the influence of solar cycle phase; and (3) Mayaud [2528] geomagnetic index aa for geomagnetic activity impacts. For this study, foF2 diurnal variation is analyzed by considering seasonal impacts.

\subsection{Methods}

2.2.1. Method for Determining the Geomagnetic Activity. Based on the strong correlation between geomagnetic index Aa and solar wind velocity established by [18], it is wellknown, according to [29-31], that disturbed activities are characterized by $\mathrm{Aa}>20 \mathrm{nT}$ and are classified into three groups: (1) recurrent activity due to both the solar high wind stream and the corotating interaction region (CIRs), (2) shock activity due to the coronal mass ejections (CMEs) and the magnetic clouds, and (3) fluctuating activity; consequences of the fluctuation of solar heliosheet and quiet activities are characterized by $\mathrm{Aa}<20 \mathrm{nT}$. For well-known geomagnetic quiet activity impact over a season, we do not use quiet days as the reference level of foF2 time variations as previously done by $[32,33]$ but use the quietest days. It is important to note that, for a given period, [28] points out that the quietest days are obtained by taking $\mathrm{Aa}<10 \mathrm{nT}$. Aa daily values are obtained from the following website: http:// isgi.unistra.fr/data_download.php.

2.2.2. Criteria for Determining the Solar Cycle Phases. Solar cycle phases are determined by using the criteria given by [29, 32-34]: (1) minimum phase: $\mathrm{Rz}<20$, where $\mathrm{Rz}$ is the yearly average Zürich sunspot number; (2) ascending phase: $20 \leq \mathrm{Rz} \leq 100$ and $\mathrm{Rz}$ greater than the previous year's value; (3) maximum phase: $\mathrm{Rz}>100$ (for small solar cycles (solar cycles with sunspot number maximum (Rzmax) less than $100)$, the maximum phase is obtained by considering $\mathrm{Rz}>$ $0.8 \times$ Rzmax); and (4) descending phase: $100 \geq \mathrm{Rz} \geq 20$ and $\mathrm{Rz}$ less than the previous year's values.

2.2.3. Equinox and Solstice Month Determination. Over a year, the seasons are considered as (1) spring (March, April, and May), (2) summer (June, July, and August), (3) autumn (September, October, and November), and (4) winter (December, January, and February). The present paper concerns the equinoctial month's: (1) March equinox (March and April or M-A) and (2) September equinox (September and October or S-O), and the solstice time: (1) June solstice (June and July or J-J) and (2) December solstices (December and January or D-J).

2.2.4. Data Analysis Method. This paper is aimed at studying the seasonal asymmetry observed in foF2 daily time variation during equinoctial and solstice time at Dakar station, throughout the SC 21 and SC 22.
The morphological or qualitative estimation of (1) equinoctial asymmetry observed in March-April and September-October equinoxes, respectively, noted by M-A and S-O, and (2) solstice asymmetry or semiannual asymmetry, observed in June-July and December-January solstices, noted, respectively, by J-J and D-J, is given by the following equation:

$$
\sigma=\sqrt{V}
$$

where $\sigma$ is the error bars putting in data graphs and $V$ is the variance defined by $(1 / N) \sum_{i=1}^{N}\left(x_{i}-\bar{x}\right)^{2}$ with $\underline{x}$ mean value and $N$ the total number of observations for a particular dataset.

The quantitative estimation of the asymmetry is given by $\sigma$ foF2 expressed as

$$
\sigma f_{o} F 2=\frac{x_{i}^{F}-x_{i}^{L}}{x_{i}^{L}} \times 100
$$

where $x_{i}^{F}$ concerns foF2 hourly mean value for March equinox (M-A) and June solstice (J-J) and $x_{i}^{L}$ is devoted for September equinox (S-O) and December solstice (D-J).

\section{Results and Discussion}

3.1. Results. Figures 1-4 concern foF 2 and $\sigma$ foF 2 diurnal variation during the four solar cycle phases, minimum, ascending, maximum, and descending, respectively, for the solar cycles SC 21 and SC 22. The left column is devoted to foF2 diurnal profile and the right one for relative deviation diurnal variation. "(a)," "(b)," and “(c)" are devoted, respectively, for equinoctial months (M-A and S-O), solstice months (J-J and $\mathrm{D}-\mathrm{J})$, and both solstice and equinox seasons. The full line is devoted to foF2 diurnal variation of $\mathrm{M}-\mathrm{A}$, J-J, or equinox months ( $\mathrm{M}-\mathrm{A}$ and $\mathrm{S}-\mathrm{O}$ ) while the broken curve exhibits that of S-O, D-J, or solstice months (J-J and D-J).

Figure 1(a) presents a foF2 profile (left column) with double peaks, a trough located at $1200 \mathrm{LT}$ and an afternoon peak amplitude higher than the morning one. A night-time peak is observed at $2300 \mathrm{LT}$ in the S-O curve. This observation is the same as that of [8] at Korhogo station. The S-O curve is above that of M-A between $1900 \mathrm{LT}$ to $2100 \mathrm{LT}$ and after $2200 \mathrm{LT}$ to before $0000 \mathrm{LT}$ with respect to error bars shown in the M-A graph: then, the equinoctial asymmetry is highlighted from this observation. In fact, the $\sigma$ foF 2 curve (right column) shows that the S-O foF2 values are always greater than those of M-A, except after $0100 \mathrm{LT}$ to before $0300 \mathrm{LT}$, during daytime (after $0800 \mathrm{LT}$ to before $1000 \mathrm{LT}$ and from 1400 LT to $1700 \mathrm{LT}$ ) and during night time (after $2100 \mathrm{LT}$ to before $2300 \mathrm{LT})$. The $\sigma$ foF 2 minimum value $(-38 \%)$ is seen at $2300 \mathrm{LT}$, and its maximum value $(+46 \%)$ is seen at $2200 \mathrm{LT}$.

Figure 1(b) shows a foF2 profile (left column) with two peaks and a trough located at 1200 LT for the D-J curve. The morning peak amplitude (located at $1000 \mathrm{LT}$ ) is higher than the afternoon one located at 1400 LT. In the J-J curve, we observe an afternoon peak at 1700 LT. This graph 


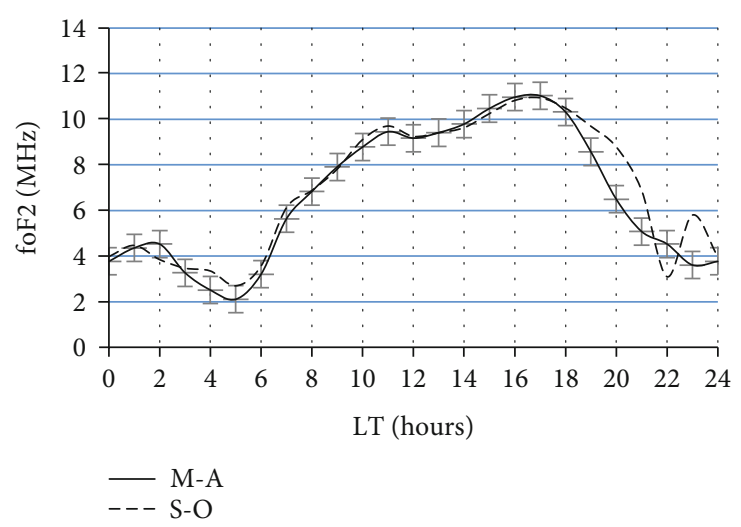

(a)

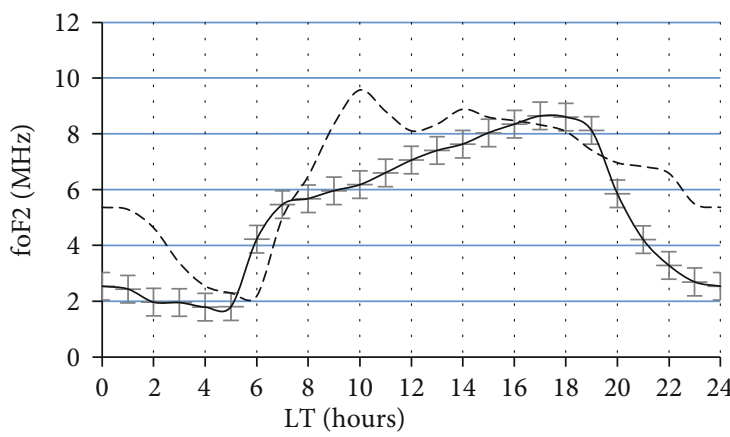

- J-J

- - - D-J

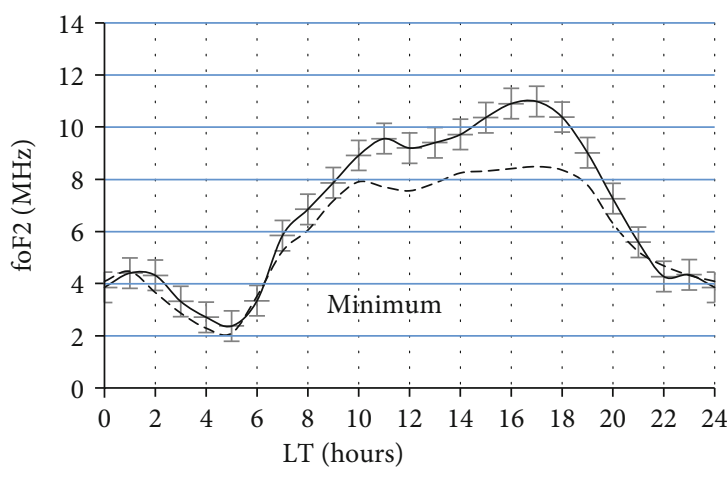

-Equinox

---Solstice

(c)
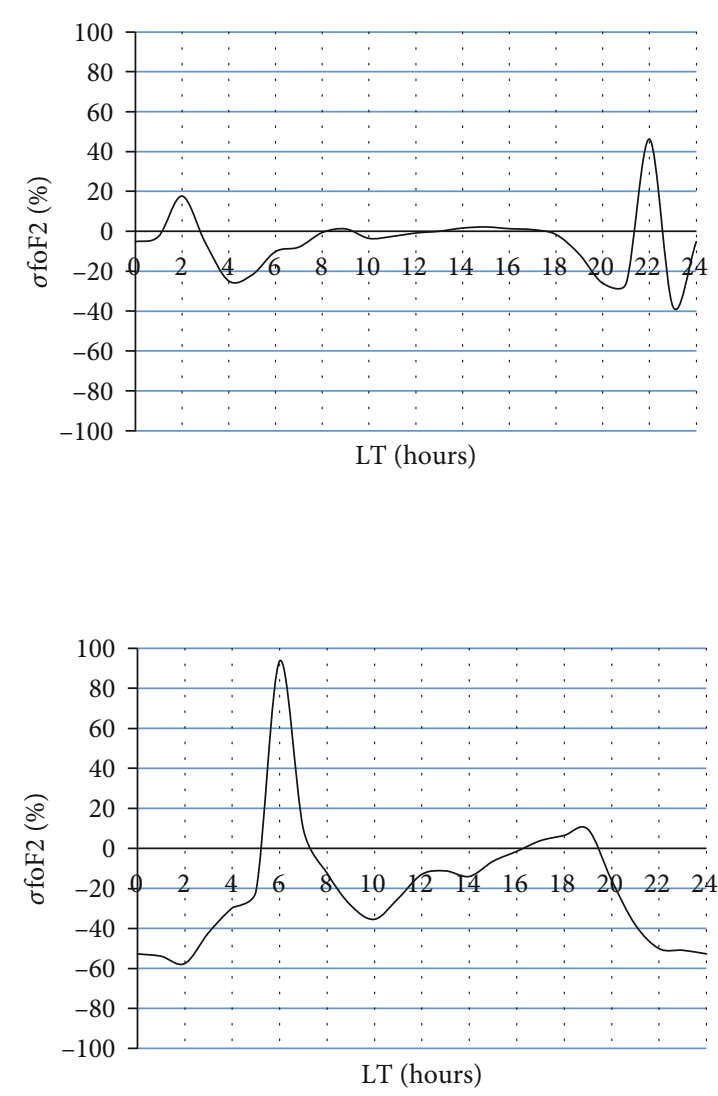

(b)

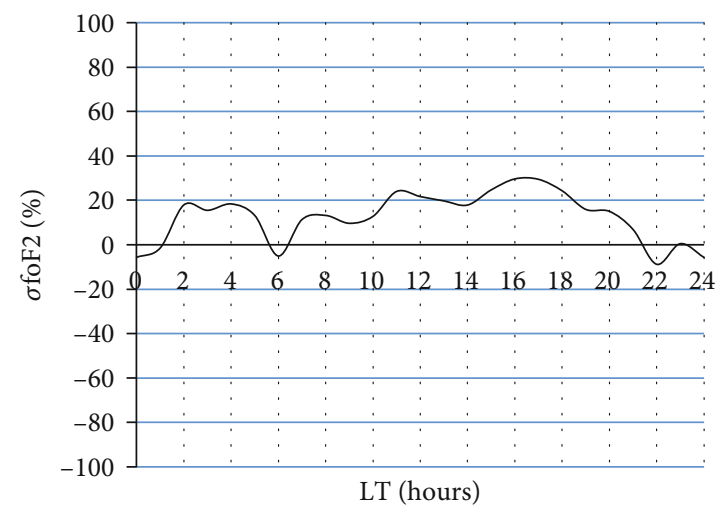

FIgURe 1: foF2 and $\sigma$ foF2 diurnal variation for the minimum phase. (a) Concerns the equinox0 months, (b) for solstice months, and (c) for the comparison between equinox time and solstice months. The left columns are devoted for the foF 2 diurnal profiles and the right one for the relative deviation percentage of the foF 2 values ( $\sigma \mathrm{foF} 2)$.

highlights solstice asymmetry due to the different morphology of profile; in fact, J-J foF2 values are greater than those of D-J from $0500 \mathrm{LT}$ to $0700 \mathrm{LT}$ and they are lower than the D-J foF2 values from $0800 \mathrm{LT}$ to $1500 \mathrm{LT}$ and $2000 \mathrm{LT}$ to $0500 \mathrm{LT}$ with respect to error bars shown in the J-J graph. $\sigma$ foF2 values (in (b)) highlight that D-J foF2 values are always greater than those of J-J except after $0500 \mathrm{LT}$ to $0700 \mathrm{LT}$ and from 1600 LT to after 1900 LT. $\sigma$ foF2's minimum value $(-58 \%)$ is seen at $0200 \mathrm{LT}$, and its maximum value (+94\%) is observed at $0600 \mathrm{LT}$.

Figure 1(c) shows a foF2 profile (left column) with two peaks and a trough located at $1200 \mathrm{LT}$ for both curves. The morning peaks' amplitude (located at $1000 \mathrm{LT}$ for solstice month and 1100 LT for equinox time) is smaller than that 


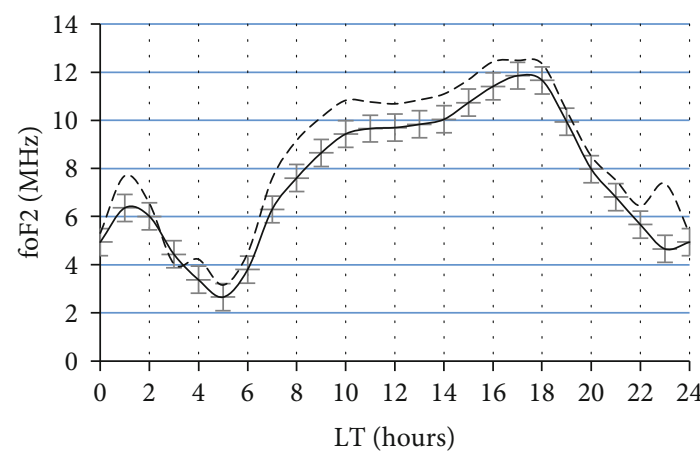

$$
\text { M-A }
$$$$
---\mathrm{S}-\mathrm{O}
$$

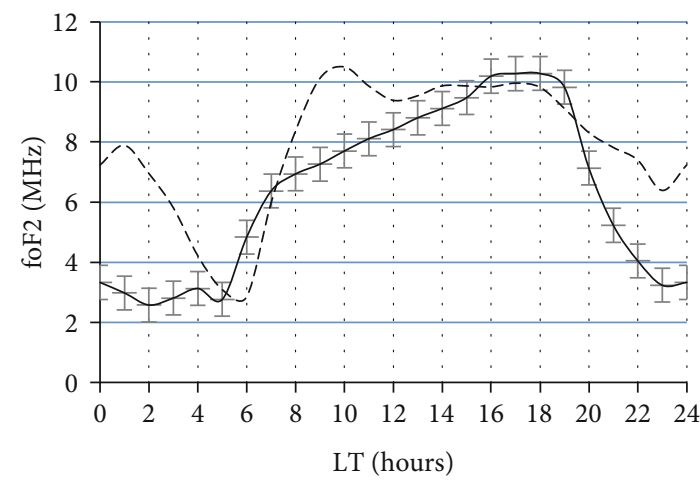

J-J

$---\mathrm{D}-\mathrm{J}$

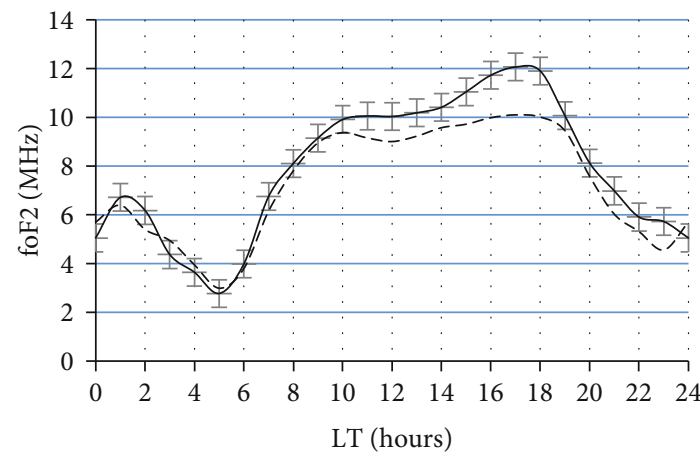

Equinox

--- Solstice

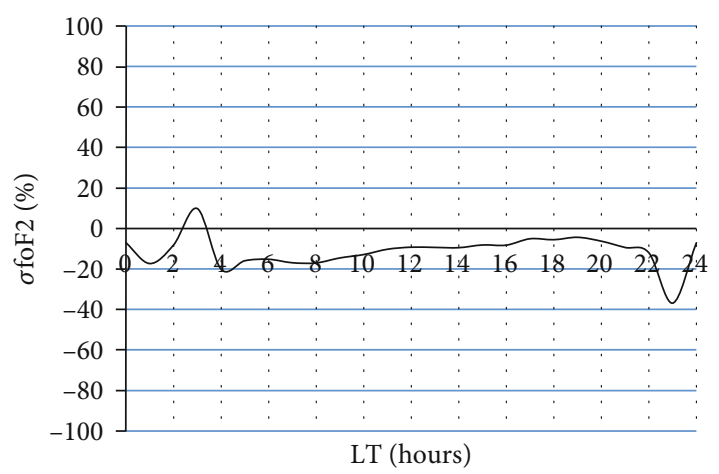

(a)

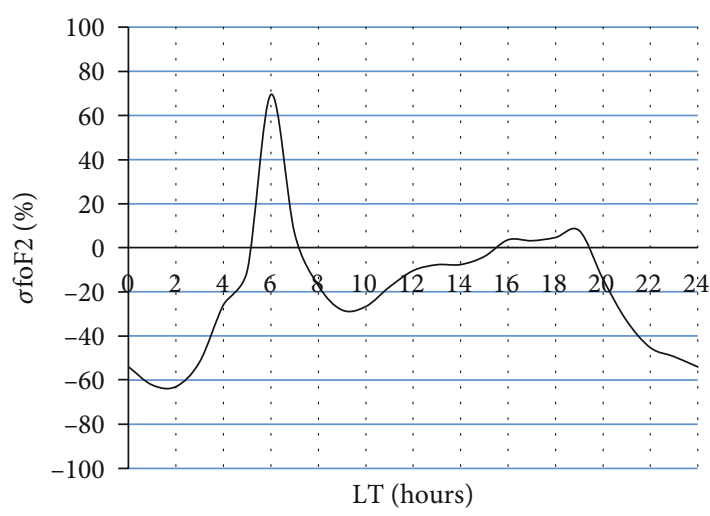

(b)

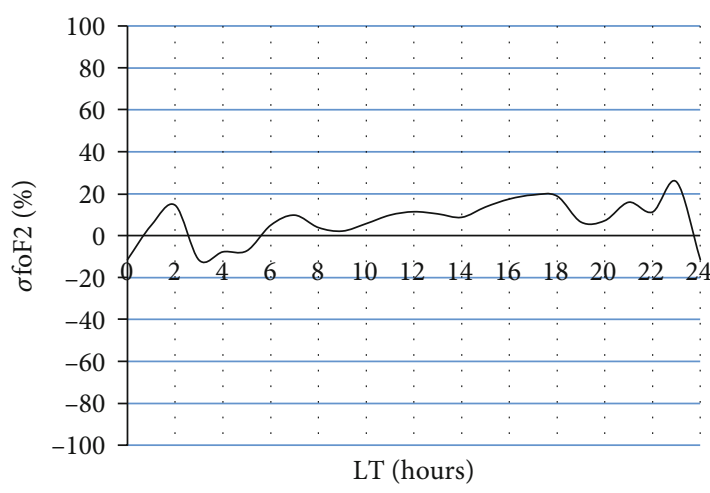

(c)

Figure 2: The same as Figure 1 but for the solar cycle increasing phase.

of the afternoon located at 1700 LT. The semiannual asymmetry is highlighted because the equinox curve is always above that of the solstice, mostly during daytime. $\sigma$ foF2 values highlight that equinox foF 2 values are always greater than those of solstice except during night time (2200 LT et de 0000-0100 LT) and before sunrise (0500 LT). The maximum negative value (-9\%) is observed at $2200 \mathrm{LT}$, and its maximum positive value $(+30 \%)$ is observed closely to the afternoon peak meantime (1600-1700 LT).

Figure 2 is devoted to increasing phase. Figure 2(a) concerns the graphs of equinox months. The foF2 diurnal profile curves show double peaks with a trough at $1200 \mathrm{LT}$ and an afternoon peak greater than the one of the morning. Only the S-O graph presents a night-time peak at 

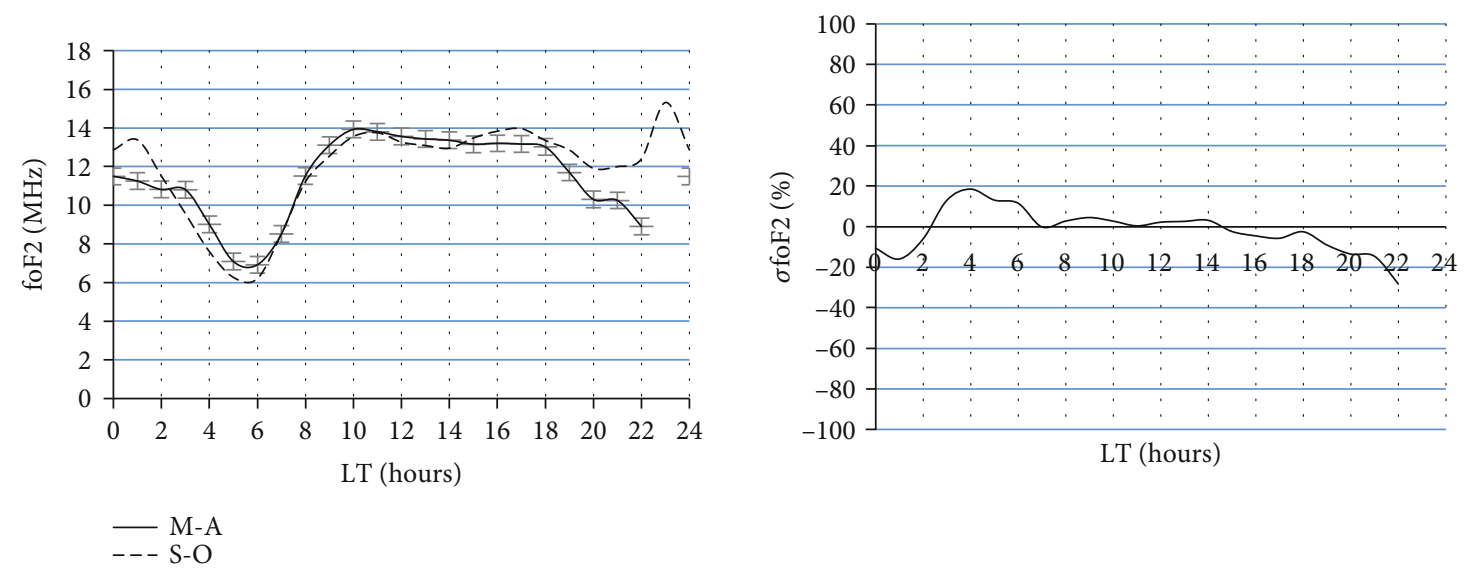

(a)
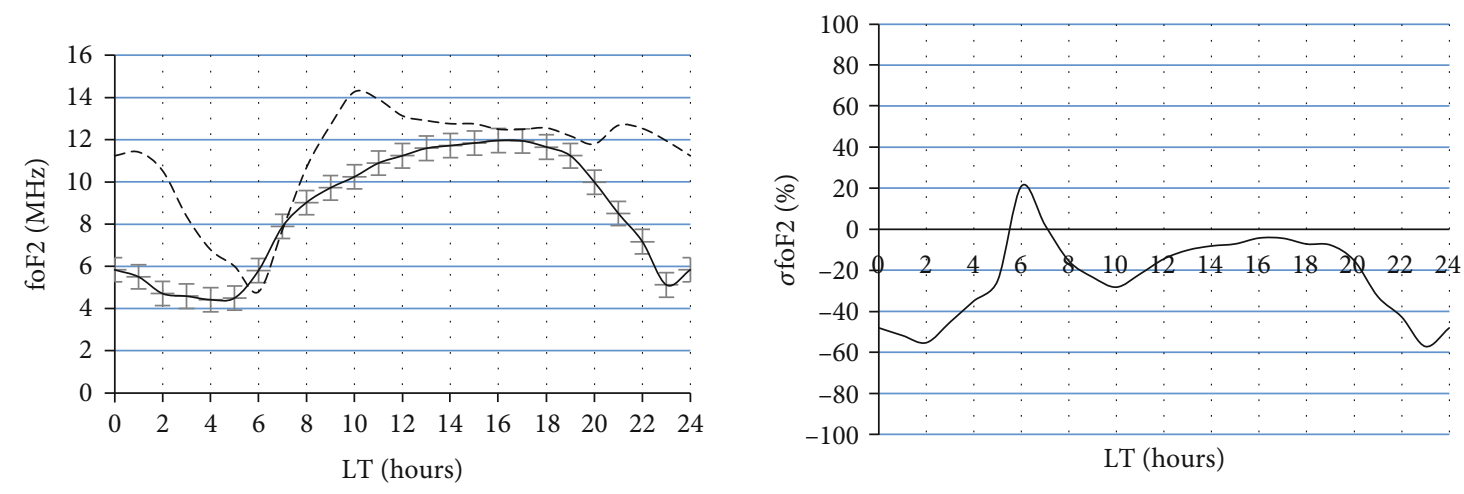

- J-J

(b)
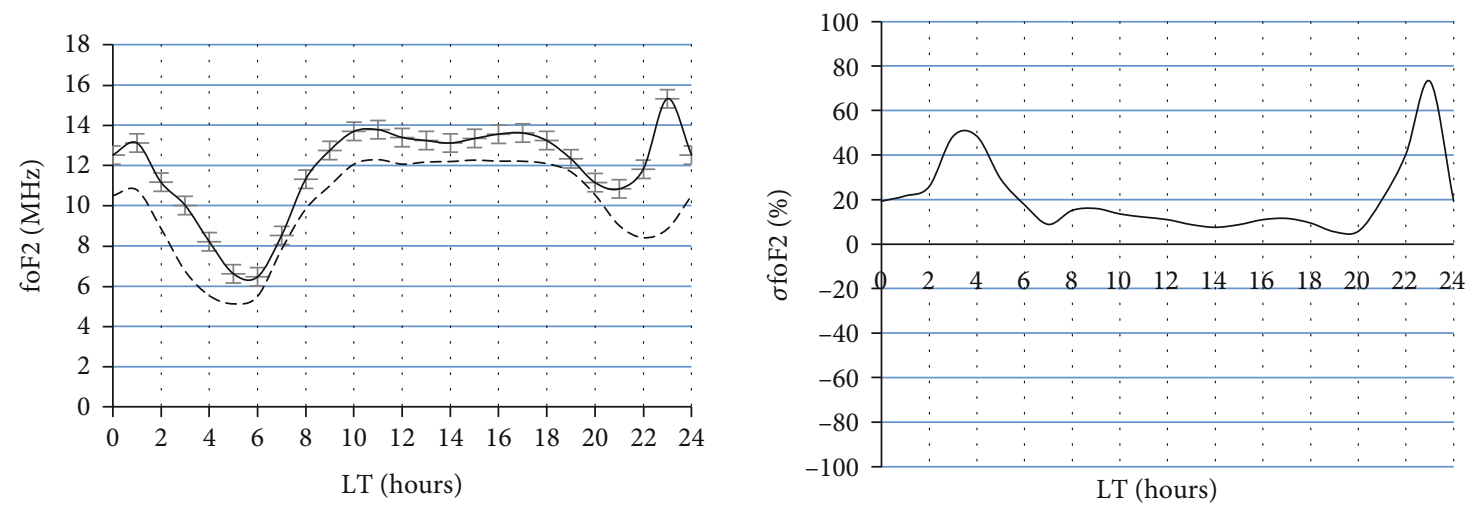

- Equinox

(c)

FIgURE 3: The same as Figure 1 but for the solar cycle maximum phase.

2300 LT. Both curves show the difference during all the day time (0700-1700 LT) and during night time (2200$0200 \mathrm{LT}$, except around 0000-0100 LT) with respect to error bars shown in the M-A graph. This situation shows the equinoctial asymmetry. $\sigma \mathrm{foF} 2$ values are negative all the time except around 0300 LT. Thus, M-A foF2 values are always lower than those of S-O, except at 0300 LT. The only positive value of $\sigma \mathrm{foF} 2(+10 \%)$ is observed at
0300 LT while its maximum negative value $(-37 \%)$ is observed at $2300 \mathrm{LT}$.

Figure 2(b) shows solstice month curves. Three peaks are observed with two troughs (one located at 1200 LT and another one at $1600 \mathrm{LT}$ ) for the D-J curve. The morning peak amplitude (located at $1000 \mathrm{LT}$ ) is higher than the one of the afternoon. The J-J curve shows an afternoon peak at $1700 \mathrm{LT}$, one hour after the second-afternoon peak of D-J. Only the D- 


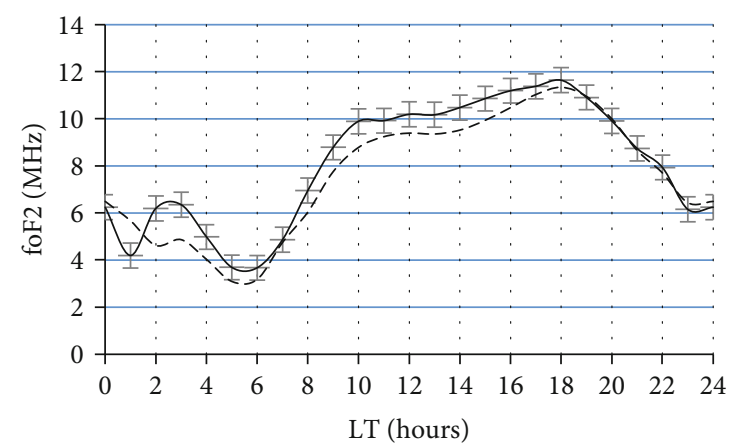

- M-A $--\mathrm{S}-\mathrm{O}$

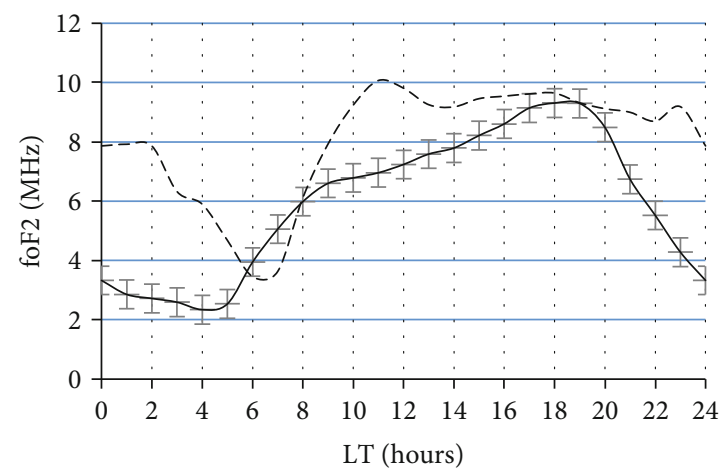

- J-J

$---\mathrm{D}-\mathrm{J}$

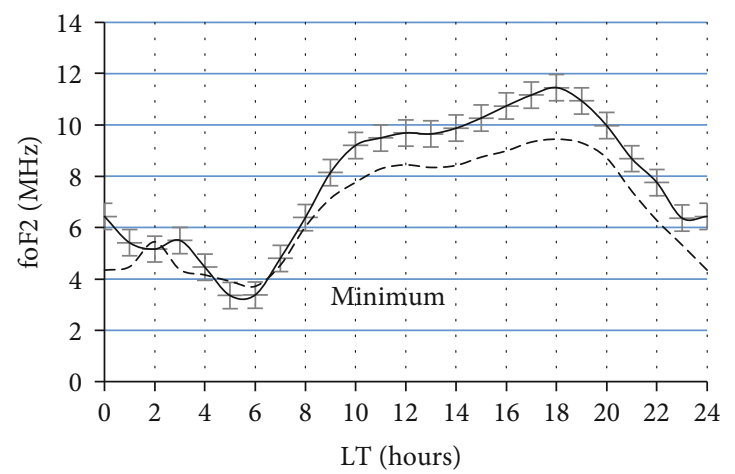

Equinox
--- Solstice

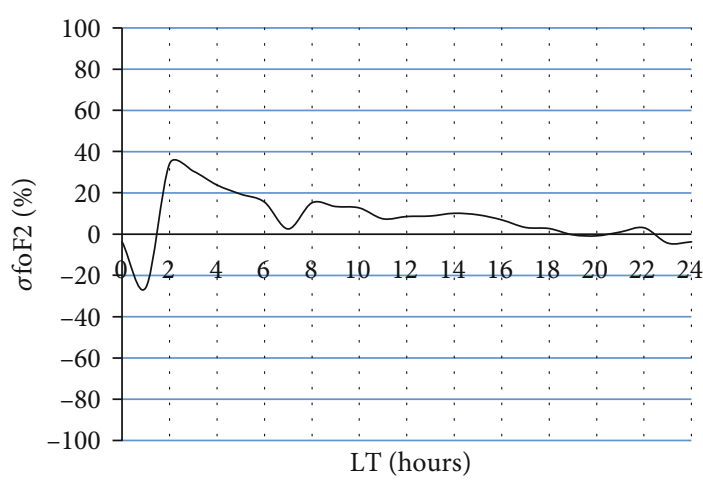

(a)

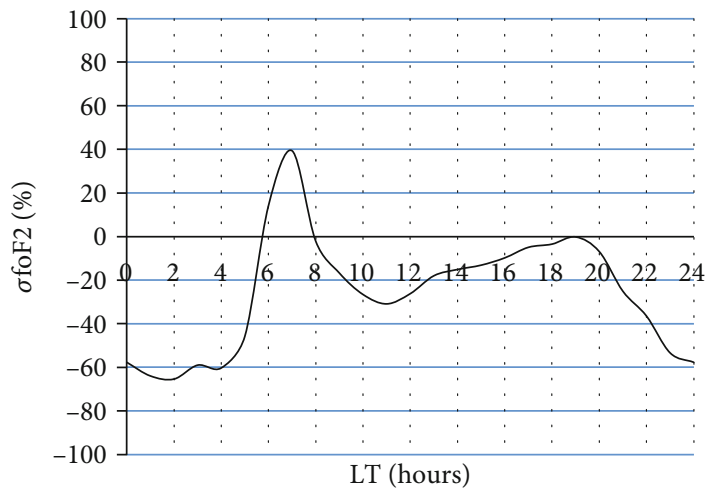

(b)

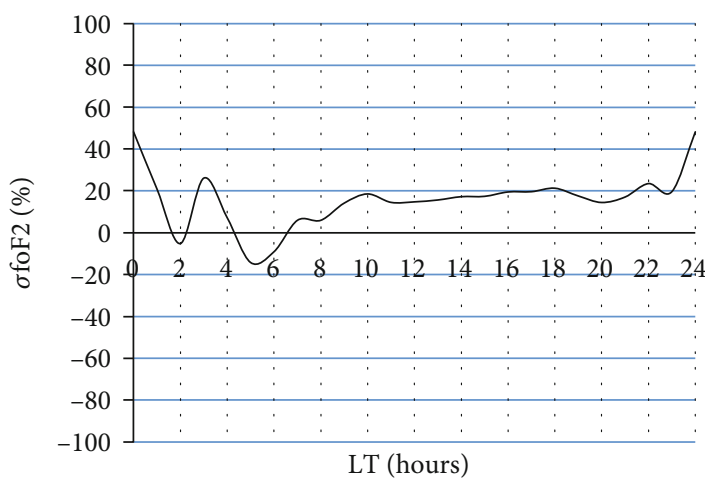

(c)

FIgURE 4: The same as Figure 1 but for the solar cycle decreasing phase.

J graph presents a night-time peak at $0100 \mathrm{LT}$. The difference between both profiles highlights the asymmetry of the solstice; in fact, JJ's foF2 values are higher than those of DJ from $0500 \mathrm{LT}$ to $0700 \mathrm{LT}$ and they are lower from $0800 \mathrm{LT}$ to 1500 LT and from $2000 \mathrm{LT}$ to $0500 \mathrm{LT}$ with respect to error bars shown in JJ's graph. $\sigma$ foF 2 values show that D-J foF2 values are always greater than those of J-J except from $0500 \mathrm{LT}$ to 0700 LT and from 1600 LT to after 1900 LT. $\sigma$ foF2's maxi- mum negative value (-63\%) is observed at $0200 \mathrm{LT}$, and its maximum positive value $(+70 \%)$ is observed at $0600 \mathrm{LT}$.

Figure 2(c) shows a foF2 profile with two peaks and a trough located at $1200 \mathrm{LT}$ for both curves, but the trough of equinox months is not very marked like the one of solstice month. The morning peak amplitude (located at 1000 LT) is smaller than that of the afternoon located at $1700 \mathrm{LT}$. Then, the semiannual asymmetry is highlighted because the 
equinox curve is always above that of the solstice, mostly during daytime (1000-1800 LT). Besides, $\sigma$ foF2 values show that equinox month foF 2 values are always greater than those of solstice except around 0000 LT and before sunrise (03000500 LT). $\sigma$ foF2's maximum negative value $(-12 \%)$ is observed at $0300 \mathrm{LT}$, and its maximum positive value $(+26 \%)$ is observed at $2300 \mathrm{LT}$.

Figure 3 concerns maximum phase curves. Figure 3(a) shows equinox month graphs. The S-O curve presents double peaks with a trough at $1200 \mathrm{LT}$, and the one of M-A shows a morning peak. Only the S-O graph presents a night-time peak at $2300 \mathrm{LT}$, and it is important to note a lack of value observed at $2300 \mathrm{LT}$ for the $\mathrm{M}-\mathrm{A}$ graph. The equinoctial asymmetry observed during night time is more expressed by the difference in terms of values from 1900 to $0100 \mathrm{LT}$ and from 0300 to $0500 \mathrm{LT}$ with respect to error bars shown in the M-A graph. $\sigma$ foF2 values are negatives from 0000 to $0200 \mathrm{LT}$, around $0700 \mathrm{LT}$ and from 1500 to $2200 \mathrm{LT}$. Thus, $\mathrm{M}-\mathrm{A}$ foF2 values are lower than those of S-O during these periods and they are greater before sunrise (0300-0600 LT) and during daytime (0800-1400 LT). $\sigma$ foF2's maximum negative value $(-28 \%)$ is observed at $2200 \mathrm{LT}$, and its maximum positive $(+19 \%)$ is seen at $0400 \mathrm{LT}$.

Figure 3(b) concerns solstice month's curves. Three peaks are observed with two troughs (first at 1700 LT and second at $2000 \mathrm{LT}$ ) for the D-J curve. This curve's morning peak amplitude $(14.27 \mathrm{MHz})$, observed at $1000 \mathrm{LT}$, is higher than that of afternoon and night. In the J-J curve, an afternoon peak at 1600 LT can be observed. D-J's curve shows a night-time peak at $2100 \mathrm{LT}$, but the J-J one does not. This figure highlights solstice asymmetry due to the difference of both profiles; in fact, J-J foF 2 values are lower than the D-J foF2 values all the time, except after sunrise (0500-0700 LT) with respect to error bars shown in the J-J graph. In fact, $\sigma$ foF2 graph highlights that D-J foF2 values are always greater than those of J-J except after 0500 LT to $0700 \mathrm{LT}$. $\sigma$ foF2's minimum value $(-57 \%)$ is seen at $2300 \mathrm{LT}$, and its maximum value $(+21 \%)$ is observed at $0600 \mathrm{LT}$.

Figure 3(c) shows a foF2 profile with two peaks and a trough located at $1400 \mathrm{LT}$ for the equinox month curve; the morning peak amplitude $(13.78 \mathrm{MHz})$, located at $1100 \mathrm{LT}$, is fairly equal to the afternoon one located at 1700 LT. On the other hand, the solstice month curve presents a profile like a plateau with a light trough at $1200 \mathrm{LT}$. The equinox month curve shows a night-time peak $(15.32 \mathrm{MHz})$ at 2300 LT, but one of solstice months does not. The semiannual asymmetry is highlighted because the equinox curve is always above that of solstice all the time except during the sunrise (0600-0700 LT) and the sunset (1900-2000 LT). $\sigma$ foF2's values highlight that foF2 values of equinox months are always higher than those of solstice months because their values are positive with a maximum $(+73 \%)$ observed at 2300 LT.

Figure 4 concerns decreasing phase curves. Figure 4(a) presents equinox month curves. Both curves show an afternoon peak with a slight trough observed at 1300 LT and a night-time peak at $0300 \mathrm{LT}$. The M-A graph is always above that of S-O, except during night time (2300 LT-0100 LT). This situation shows equinoctial asymmetry which is more expressed during day time (0800-1600 LT) and during night time (0000 LT-0100 LT and 0200-0500 LT) with respect to error bars shown in the M-A graph. Besides, $\sigma$ foF 2 values are positives during all the time, except from 1900 to 2000 LT and from 2300 to 0100 LT. Therefore, M-A's foF2 values are lower than those of S-O during these periods and they are greater during the left time. The $\sigma$ foF 2 minimum value $(-26 \%)$ is observed at $0100 \mathrm{LT}$, and the maximum one $(+34 \%)$ is observed at $0200 \mathrm{LT}$.

Figure 4(b) concerns solstice month curves. Three peaks are observed with two troughs (one located at 1400 LT and another one at $2200 \mathrm{LT}$ ) for the D-J curve. The morning peak amplitude, located at $1100 \mathrm{LT}$, is higher than the afternoon one. The J-J curve shows an afternoon peak at 1800 LT. DJ's graph presents a night-time peak at $2300 \mathrm{LT}$, but the J-J one does not. The difference of both profiles' morphology highlights solstice asymmetry; in fact, J-J foF2 values are lower than the D-J foF2 values during all the time, except during sunrise (0600-0800 LT) with respect to error bars shown in the J-J graph. $\sigma$ foF2's values are always negative except at sunrise (0600-0700 LT) with a maximum negative value $(-65 \%)$ observed at $0200 \mathrm{LT}$ and a maximum positive one $(+39 \%)$ observed at $0700 \mathrm{LT}$.

Figure 4(c) presents equinox and solstice month graphs. All foF2's profiles show an afternoon peak with a slight trough located at 1300 LT. Both graphs present a nighttime peak, observed at 0200 LT for solstice months and at 0300 LT for equinoxes. The equinox curve is always above that of solstice all the time, except around 0200 LT and during the sunrise (0500-0600 LT); hence, the semiannual asymmetry is highlighted. $\sigma$ foF2's values highlight the observation that the foF 2 values of equinox months always remain higher than those of solstice months at all times except around 0200 LT and at sunrise (0500-0600 LT). The maximum positive value $(+48 \%)$ is observed at $0000 \mathrm{LT}$, and the maximum negative one $(-14 \%)$ is observed at $0500 \mathrm{LT}$.

3.2. Discussion. It emerges from this study that in general, equinoctial asymmetry is less pronounced at Dakar station [35] and somewhere is absent during day time for all solar cycle phases. Equinoctial asymmetry is due to an asymmetry of ionization during both equinoxes, despite the fact that solar zenithal angle kept the same characteristics during both equinoxes. This subject has been widely discussed in recent publications [8, 19-21, 36, 37]. Many mechanisms have been suggested to explain this asymmetry such as ionospheric electric field variation, geomagnetic activity, solar wind change through the equinoxes, thermosphere chemical composition asymmetric variation, and Russell-McPherron mechanism. [13] at Niamey station and [8] at the one of Korhogo suggest that the equinoctial asymmetry is mainly due to the Russell-McPherron mechanism for all seasons (spring and autumn) at those African equatorial anomaly regions of the ionosphere. Then, one can expect to have "no equinoctial asymmetry" during the equinox months.

But, [6] suggests that, even if the Russell-McPherron impact is the main explicative mechanism of equinoctial asymmetry, it remains important to find other mechanisms which could explain this phenomenon. From their work on 
the satellite ROCSAT-1 observation from 1994 to 2004, [21, 38] suggest that equinoctial asymmetry is due to the asymmetry in vertical drift velocity $E \times B$ at the ionosphere of equatorial latitude. They also suggest that the asymmetry in the PRE mechanism may be related to the asymmetry in the eastward thermosphere winds. Nevertheless, we observe a PRE asymmetry because it occurs during autumn and not during spring. Then, vertical drift velocity $E \times B$ at the equatorial latitude ionosphere has also been suggested to explain the equinoctial asymmetry as suggested by [20].

The solstice asymmetry, called winter anomaly, is observed throughout all solar cycle phases. $\sigma$ foF2's maximum negative value (-65\%) is observed during the decreasing phase, and its maximum positive one $(+94 \%)$ is observed during the minimum phase. In general, the night-time peak observed in D-J's curve is not observed in J-J's graph. Besides, D-J's curve (winter) is over the J-J's one (summer); then, the winter anomaly is obvious and it remains during night time contrary to the conclusion of [39]. Some authors suggest that this asymmetry may be due to neutral composition variation [8, 39-45]. According to [43], this change may induce an enhancement of the $\mathrm{O} / \mathrm{N}_{2}$ ratio due to convection of atomic oxygen from the summer hemisphere to the winter one. Otherwise, for [46, 47], this abnormal variation of the neutral composition of the ionosphere's $\mathrm{F}$ region may be associated with the seasonal variation of the thermosphere winds. According to [48], asymmetric variations of aeronomic parameters between winter and summer, the main ones being the thermospheric parameters, the intensity of EUV radiations, the recombination rate $\beta$, and the atomic oxygen concentration [O] are responsible for the winter anomaly phenomenon. If according to [23], this anomaly is due to the intensity of solar radiation intensity due to change in the Earth-Solar distance between December solstice (Earth is at perigee) and June solstice (Earth is at apogee), the flux of solar ionization radiation cannot be the only factor as concluded by [22]. Our results show that the difference between winter and summer is mainly due to the amplitude of solar high-speed wind. As this type of wind can be a source of interplanetary corpuscular radiation, then, the annual asymmetry observed may be due to [24]'s process.

The semiannual asymmetry is observed during the day over all solar cycle phases. It is more observed during night time for maximum and decreasing phases than the minimum and increasing phases. This phenomenon is characterized by a predominance of ionization during equinoctial months than during solstices. Numerous researches have been done concerning it. [49] suggests that at the equatorial ionosphere latitudes, it may be explained by asymmetry observed in vertical drift velocity $E \times B$. Nevertheless, we observe an absence of asymmetry in the vertical drift velocity $E \times B$; thus, the vertical drift velocity $E \times B$ cannot be the source of the semiannual anomaly. Otherwise, if [50] suggests that it can be explained by the variation of the terrestrial high atmosphere temperature variation, according to $[40,51]$, it is due to semiannual variation of neutral atmosphere density at low latitudes with the geomagnetic activity. The axial mechanism suggested by [52] contributes widely to explain the semiannual anomaly. In fact, during equinox months, the Earth is exposed to the solar high wind stream because of its heliographic latitude of about $7^{\circ}$. Further, [53] suggests the existence of a phenomenon called "thermospheric spoon" which is an interhemispheric circulation on a global scale at the solstice. It would act like a huge turbulent vortex mixing the major thermosphere's species. These vortices tend to reduce the oxygen atomic density of solstice months compared to the equinox. This phenomenon causes atmosphere "compression" at solstices which may explain the semiannual anomaly. In addition, from the analysis of satellites TIMED/GUVI's observations and model studies (e.g., TIE-GCM), [54] shows that there is a diffusion of vortices in the mesopause region. These vortex diffusions are called the vortex mixing phenomenon, being more important during solstices than equinoxes; they would therefore be one of the causes of semiannual asymmetry.

\section{Conclusion}

This paper shows that the equinoctial asymmetry is less pronounced at Dakar station. The solstice asymmetry (annual anomaly) is observed during all solar cycle phases. The semiannual asymmetry is observed over all solar cycle phases; it is more expressed during the night for maximum and decreasing phases than during minimum and increasing phases. The maximum negative value of $\sigma \mathrm{foF} 2(-65 \%)$ is observed at the decreasing phase, and its maximum positive one $(+94 \%)$ is observed at the minimum phase. In general, night-time peaks observed during the months of D-J and S-O are not observed in those of J-J and M-A, respectively. Thus, there is an equinoctial, annual, and semiannual asymmetry in the PRE mechanism.

\section{Data Availability}

The sunspot data used to support the findings of our study are available at http://www.sidc.be/silso/datafiles. The geomagnetic aa index data are available at http://isgi.unistra.fr/ data_download.php.

\section{Conflicts of Interest}

The authors declare no conflicts of interest.

\section{Acknowledgments}

The authors thank Brest Telecom of Bretagne for providing Dakar ionosonde data. Many thanks to ISGI data center for providing their data center.

\section{References}

[1] W. H. Campbell, "Annual and semiannual changes of the quiet daily variations (Sq) in the geomagnetic field at north American locations," Journal of Geophysical Research, vol. 87, no. A2, pp. 785-796, 1982.

[2] E. W. Cliver, Y. Kamide, and A. G. Ling, "Mountains versus valleys: semiannual variation of geomagnetic activity," Journal of Geophysical Research, Space Physics, vol. 105, no. A2, pp. 2413-2424, 2000. 
[3] E. W. Cliver, Y. Kamide, and A. G. Ling, "The semiannual variation of geomagnetic activity: phases and profiles for 130 years of aa data," Journal of Atmospheric and SolarTerrestrial Physics, vol. 64, no. 1, pp. 47-53, 2002.

[4] E. W. Cliver, L. Svalgaard, and A. G. Ling, "Origins of the semiannual variation of geomagnetic activity in 1954 and 1996," Annals of Geophysics, vol. 22, no. 1, pp. 93-100, 2004.

[5] N. U. Crooker, E. W. Cliver, and B. T. Tsurutani, "The semiannual variation of great geomagnetic storms and the postshock Russell-McPherron effect preceding coronal mass ejecta," Geophysical Research Letters, vol. 19, no. 5, pp. 429-432, 1992.

[6] N. Beloff and E. O. Falayi, "Global study of geomagnetic induced current using time derivative of geomagnetic fields," Canadian Journal of Pure and Applied Science, vol. 3, no. 3, pp. 943-951, 2009.

[7] W. D. Gonzalez, A. L. Clúa de Gonzalez, and B. T. Tsurutani, "Comment on "The semiannual variation of great geomagnetic storms and the postshock Russell-Mcpherron effect preceding coronal mass ejecta" by N. U. Crooker, E. W. Cliver and B. T. Tsurutani," Geophysical Research Letters, vol. 20, no. 15, pp. 1659-1660, 1993.

[8] K. Guibula, F. Ouattara, and D. A. Gnabahou, "foF2 seasonal asymmetry time variation at Korhogo station from 1992 to 2002," International Journal of Geosciences, vol. 9, no. 4, pp. 207-213, 2018.

[9] P.-N. Mayaud, "Comment on 'Semiannual variation of geomagnetic activity' by C. T. Russell and R. L. McPherron,” Journal of Geophysical Research, vol. 79, no. 7, 1974.

[10] D. H. McIntosh, "On the annual variation of magnetic disturbance," Philosophical Transactions of the Royal Society of London. Series A, Mathematical and Physical Sciences, vol. 251, no. 1001, 1959.

[11] M. Mendillo, C.-L. Huang, X. Pi, H. Rishbeth, and R. Meier, "The global ionospheric asymmetry in total electron content," Journal of Atmospheric and Solar-Terrestrial Physics, vol. 67, no. 15, pp. 1377-1387, 2005.

[12] K. Mursula, E. Tanskanen, and J. J. Love, "Spring-fall asymmetry of substorm strength, geomagnetic activity and solar wind: implications for semiannual variation and solar hemispheric asymmetry," Geophysical Research Letters, vol. 38, no. 6, 2011.

[13] F. Ouattara, J.-L. Zerbo, M. Kaboré, and R. Fleury, "Investigation on equinoctial asymmetry observed in Niamey Station Center for Orbit Determination in Europe Total Electron Content (CODG TEC) variation during solar cycle 23," International Journal of Physical Sciences, vol. 12, no. 22, pp. 308-321, 2017.

[14] P. Rashmi, S. B. Singh, and B. Kalyan, "A study of seasonal variation of geomagnetic activity," Research Journal of Physical and Applied Sciences, vol. 2, no. 1, pp. 1-11, 2013.

[15] C. T. Russell and R. L. McPherron, "Semiannual variation of geomagnetic activity," Journal of Geophysical Research, vol. 78, no. 1, pp. 92-108, 1973.

[16] L. Svalgaard, E. W. Cliver, and A. G. Ling, "The semiannual variation of great geomagnetic storms," Geophysical Research Letters, vol. 29, no. 16, pp. 12-1-12-4, 2002.

[17] H. Zhao and Q. G. Zong, "Seasonal and diurnal variation of geomagnetic activity: Russell-McPherron effect during different IMF polarity and/or extreme solar wind conditions," Journal of geophysical research, vol. 117, no. A11, article A11222, 2012.
[18] L. Svalgaard, Geomagnetic activity: dependence on solar wind parameters, Stanford Univ Calif Inst For Plasma Research, 1977.

[19] E. A. Essex, "Equinoctial variations in the total electron content of the ionosphere at northern and southern hemisphere stations," Journal of Atmospheric and Terrestrial Physics, vol. 39, no. 5, pp. 645-650, 1977.

[20] Y. Chen, L. Liu, W. Wan, and Z. Ren, "Equinoctial asymmetry in solar activity variations of $\mathrm{NmF} 2$ and TEC," Annales of Geophysicae, vol. 30, no. 3, pp. 613-622, 2012.

[21] Z. Ren, W. Wan, L. Liu, Y. Chen, and H. Le, "Equinoctial asymmetry of ionospheric vertical plasma drifts and its effect onF-region plasma density," Journal of geophysical research, vol. 116, no. A2, 2011.

[22] H. Rishbeth and I. C. F. Müller-Wodarg, "Why is there more ionosphere in January than in July? The annual asymmetry in the F2-layer," Annales Geophysicae, vol. 24, no. 12, pp. 3293-3311, 2006.

[23] M. J. Buonsanto, "Possible effects of the changing earth \pm sun distance on the upper atmosphere," Pacific Journal of Natural Science, vol. 8, pp. 58-65, 1986.

[24] T. Yonezawa, "On the seasonal and non-seasonal annual variations and the semi-annual variation in the noon and midnight electron densities of the F_2 layer in middle latitudes," Journal of the Radio Research Laboratory, vol. 6, pp. 293309, 1959.

[25] P. N. Mayaud, A hundred year series of geomagnetic data, 1868-1967: indices aa, storm sudden commencements, vol. 33, no. 33, 1973IAGA Bulletin, 1973.

[26] P. N. Mayaud, “Theaaindices: a 100-year series characterizing the magnetic activity," Journal of Geophysical Research, vol. 77, no. 34, pp. 6870-6874, 1972.

[27] P. N. Mayaud, “Une mesure planétaire d'activité magnétique basée sur deux observatoires antipodaux," Annales de Geophysique, vol. 27, no. 1, pp. 67-70, 1971.

[28] P. N. Mayaud, "Derivation, meaning, and use of geomagnetic indices," Geophysical Monograph Series, vol. 22, 1980.

[29] F. Ouattara and C. Amory-Mazaudier, "Solar-geomagnetic activity and Aa indices toward a standard classification," Journal of Atmospheric and Solar-Terrestrial Physics, vol. 71, no. 17-18, pp. 1736-1748, 2009.

[30] F. Ouattara and J.-L. Zerbo, "Ouagadougou station F2 layer parameters, yearly and seasonal variations during severe geomagnetic storms generated by coronal mass ejections (CMEs) and fluctuating wind streams," International Journal of the Physical Sciences, vol. 6, no. 20, pp. 4854-4860, 2011.

[31] J.-L. Zerbo, C. Amory Mazaudier, F. Ouattara, and J. D. Richardson, "Solar wind and geomagnetism: toward a standard classification of geomagnetic activity from 1868 to 2009," Annals of Geophysics, vol. 30, no. 2, pp. 421-426, 2012.

[32] J.-L. Zerbo, F. Ouattara, C. Zoundi, and A. M. F. Gyébré, “Solar cycle 23 and geomagnetic activity since 1868," Rev.CAMESSérie A, vol. 12, no. 2, pp. 255-262, 2011.

[33] D. A. Gnabahou and F. Ouattara, "Ionosphere variability from 1957 to 1981 at Djibouti station," European Journal of Scientific Research, vol. 73, no. 3, pp. 382-390, 2012.

[34] F. Ouattara, "Relationship between geomagnetic classes' activity phases and their occurrence during the sunspot cycle," Annales de Geophysique, vol. 52, no. 2, pp. 107-116, 2009.

[35] A. M. Nour, O. Frédéric, Z. J. Louis, G. A. M. Frédéric, N. Emmanuel, and Z. François, "Statistical study of foF2 
diurnal variation at Dakar station from 1971 to 1996: effect of geomagnetic classes of activity on seasonal variation at solar minimum and maximum," International Journal of Geosciences, vol. 6, no. 3, pp. 201-208, 2015.

[36] T. P. O'Brien and R. L. McPherron, "Seasonal and diurnal variation of Dst dynamics," Journal of Geophysical Research, vol. 107, no. A11, 2002.

[37] N. Balan, Y. Otsuka, G. J. Bailey, and S. Fukao, "Equinoctial asymmetries in the ionosphere and thermosphere observed by the MU radar," Journal of Geophysical Research, vol. 103, no. A5, pp. 9481-9495, 1998.

[38] L. Liu, M. He, X. Yue, B. Ning, and W. Wan, "Ionosphere around equinoxes during low solar activity," Journal of Geophysical Research, vol. 115, no. A9, article A09307, 2010.

[39] H. Rishbeth, I. C. F. Müller-Wodarg, L. Zou et al., "Annual and semiannual variations in the ionospheric F2-layer: II. Physical discussion," Annals of Geophysics, vol. 18, no. 8, pp. 945-956, 2000.

[40] M. R. Torr and D. G. Torr, "The seasonal behaviour of the F2layer of the ionosphere," Journal of Atmospheric and SolarTerrestrial Physics, vol. 35, no. 12, pp. 2237-2251, 1973.

[41] D. G. Torr, M. R. Torr, and P. G. Richards, "Causes of the F region winter anomaly," Geophysical Research Letters, vol. 7, no. 5, pp. 301-304, 1980.

[42] H. Rishbeth and R. Edwards, "The isobaric F2-layer," Journal of Atmospheric and Terrestrial Physics, vol. 51, no. 4, pp. 321-338, 1989.

[43] F. S. Johnson, Composition changes in the upper atmosphere, in electron density distributions in the ionosphere and exosphere, E. Thrane, Ed., North-Holland, Amsterdam, 1964.

[44] A. G. Burns, W. Wang, L. Qian et al., "On the solar cycle variation of the winter anomaly," Journal of Geophysical Research: Space Physics, vol. 119, no. 6, pp. 4938-4949, 2014.

[45] H. Rishbeth and C. Setty, "The F-layer at sunrise," Journal of Atmospheric and Terrestrial Physics, vol. 20, no. 4, pp. 263276, 1961.

[46] R. G. Roble, R. E. Dickinson, and E. C. Ridley, "Seasonal and solar cycle variations of the zonal mean circulation in the thermosphere," Journal of Geophysical Research, vol. 82, no. 35, pp. 5493-5504, 1977.

[47] R. G. Roble, "Dynamics of the Earth's thermosphere," Reviews of Geophysics, vol. 21, no. 2, pp. 217-233, 1983.

[48] A. Mikhailov and L. Perrone, "On the mechanism of seasonal and solar cycle $N_{m} F 2$ variations: a quantitative estimate of the main parameters contribution using incoherent scatter radar observations," Journal of Geophysical Research: Space Physics, vol. 116, no. A3, 2011.

[49] R. Ma, J. Xu, and H. Liao, "The features and a possible mechanism of semiannual variation in the peak electron density of the low latitude F2 layer," Journal of Atmospheric and SolarTerrestrial Physics, vol. 65, no. 1, pp. 47-57, 2003.

[50] T. Yonezawa, "The solar-activity and latitudinal characteristics of the seasonal, non-seasonal and semi-annual variations in the peak electron densities of the F2-layer at noon and at midnight in middle and low latitudes," Journal of Atmospheric and Terrestrial Physics, vol. 33, no. 6, pp. 889-907, 1971.

[51] H. G. Mayr and K. K. Mahajan, "Seasonal variation in the $F_{2}$ region," Journal of Geophysical Research, vol. 76, no. 4, pp. 1017-1027, 1971.

[52] J. D. Bohlin, "Extreme-ultraviolet observations of coronal holes," Solar Physics, vol. 51, no. 2, pp. 377-398, 1977.
[53] T. Fuller-Rowell, "The "thermospheric spoon": a mechanism for the semiannual density variation," Journal of Geophysical Research, Space Physics, vol. 103, no. A3, pp. 3951-3956, 1998.

[54] L. Qian, S. C. Solomon, and T. J. Kane, "Seasonal variation of thermospheric density and composition," Journal of Geophysical Research: Space Physics, vol. 114, no. A1, 2009. 